\title{
The issue of drug spending
}

\author{
Abimbola Farinde
}

Correspondence: Abimbola.farinde@columbiasouthern.edu

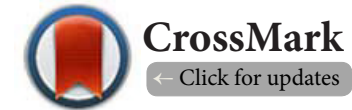

Columbia Southern University, USA.

\begin{abstract}
Drug pricing and spending has been become an ever present issue that continues to gain attention. Many Americans experience difficulty when it comes to the affordability of prescription drugs, specialty drugs, or even branded medications. According to the IMS Institute of Healthcare Information the amount of money that is tied to medications has increased by at least double digits since the second year in 2015 to reach $\$ 425$ billion. The topic of cost containment and improved regulation on the part of local, state, government officials is necessary in order to prevent additional increases that will continue to be felt by the average consumer.
\end{abstract}

Keywords: Drug spending, prices, specialty drugs, affordable care act, affordability, prescription drugs, government officials

\section{Editorial}

The topic of drug pricing and spending has continued to gain more and more attention and momentum over the last few years. Undoubtedly, this topic has been at the forefront of most conversations with many people seeking different methods to contain the continuous growth. Both organizations, politicians, and consumers continue to voice their concerns over the rising cost of drugs which in turn makes it difficult for many Americans to gain access to some of these life saving or maintenance medications. Despite the changes that have been promised by the Affordable Care Act Americans still continue to see price increases with drugs because the pharmaceutical industry was mostly unregulated [1]. According to the IMS Institute of Healthcare Informatics the amount of spending that is associated with medications has increased by at least double digits for the second year in 2015 to reach $\$ 425$ billion based on invoice prices but with adjustments for rebates and other prices the net spending was at $\$ 310$ billon [2]. This number was believed to be largely attributed to the increase in new medicine spending and release unto the market, the release of brand drugs, and spending on specialty drugs which was at $\$ 121$ billion, and has demonstrated a 15\% increase when compared to 2014 . The spending that has been observed with specialty medicines has doubled over the last five years which has significantly contributed to the spending growth that has been observed in 2010 compared to 2015. The long-term trends that have resulted from the implementation of the Af- fordable Care Act, in response to rising healthcare costs and drug spending, still continued to be observed in 2015 and is still playing a role in drug spending in 2016. While the initial goal of the Affordable Care Act was to allow for greater access and affordability of healthcare, this level of healthcare is being provided by a variety of healthcare professional across a number of facilities which is contributing to more out of pocket costs and barriers that many patients are facing to date.

The United States spending on medicines to expected to reach as high as $\$ 400$ billion in 2020 if nothing is done to achieve management and containment of the escalating price of healthcare. The plan of action is that while brand prices may continue to increase and there may be the observance of more spending on new drug development and innovations, this can be balanced with the presence of discounts, rebates, and other types of price concessions. Ultimately only time will tell if this will be the resultant outcome and if the issue of increasing drug spending will continue to be a problem that many Americans still have to face. There is may still be hope that the Affordable Care Act may an impact on the escalating drug prices for consumers but for now little is being done to rein it in. To date this continues to be a barrier that Americans face when it comes to gaining access to much needed medications. For many Americans it appears that more time will have to be given to view the full impact of the implementation of the Affordable Care Act when it starts to affect them more positively. As more of the costs are incurred by patients the

(ㄷ) 2016 Abimbola Farinde; licensee Herbert Publications Ltd. This is an Open Access article distributed under the terms of Creative Commons Attribution License (http://creativecommons.org/licenses/by/3.0). This permits unrestricted use, distribution, and reproduction in any medium, provided the original work is properly cited. 
more they will become sensitive to this fact and the more this will fuel political discussion towards a notable change.

In order for people to be able to gain and maintain access to many of the life sustaining medications that they are on a collaborative effort from local, state, and government officials must occur. There needs to be better oversight on the strategies that are taken to price medications that many Americans depend on each day. It is important for consumers to be protected and reasonable effort should be taken to ensure that medication pricing is both fair and affordable for those who need these medications.

\section{Competing interests}

The author declares that she has no competing interests.

\section{Publication history}

Editors: Monica Butnariu, Banat's University of Agricultural Sciences and Veterinary Medicine, Romania.

Francesco Trapasso, Magna Graecia University, Italy.

Received: 21-May-2016 Final Revised: 07-Jul-2016

Accepted: 25-Jul-2016 Published: 03-Aug-2016

\section{References}

1. Blank C. Top 7 new facts about drug spending. 2016. | Website

2. IMS Health. Medicine use and spending in the US-A review of 2015 and outlook of 2020. 2016. | Website

\section{Citation:}

Farinde A. The issue of drug spending. Bio Chem Comp. 2016; 4:4.

http://dx.doi.org/10.7243/2052-9341-4-4 